\title{
The Effect of Concept Mapping Strategy as a Graphical Tool in Writing Achievement among EFL Learners
}

\author{
Maryam Shakoori, Parvin Kadivar, and Reza Sarami
}

\begin{abstract}
Teaching and learning English as a language of international communication is a vital and important affair. Especially writing in English is one of the most prominent skills in this field. In spite of studying English at different levels, EFL learners are not proficient enough in this basic skill. In a semi experimental design, 28 students were selected from Danesh Gostar Foreign Language center as a sample group. After dividing them into experimental and control group, PET was administered as a pretest, both group were taught writing for 10 sessions of 75 minutes. The experimental group was taught by concept mapping and the other one practiced in traditional instruction model. The students answered the posttest one week after the end of the experiment. The data were analyzed by ANCOVA. The results indicated that the use of concept mapping was efficient in writing achievement for experimental group and. It can be concluded that the use of efficient and practical method like concept mapping as a graphical tool for representation of knowledge that emphasizes on the relationships between concepts, can facilitate and make writing achievement interesting for EFL learners and give depth and meaning to learning.
\end{abstract}

Index Terms - Writing, achievement, concept mapping, EFL learners, teaching English, graphical tool.

\section{INTRODUCTION}

Writing is a complicated process which involves a number of cognitive and metacognitive activities, for instance; brainstorming, planning, outlining, organizing, drafting, and revising. Cognitive aspects of writing have received a particular attention, as investigators have attempted to understand the thought processes underlying the compositions of students (Flower \& Hayes, 1981)[1]. Writing requires composing, which implies the ability either to tell or retell pieces of information in the form of narratives or description, or to transform information into new texts, as in expository or argumentative writing. In many societies, writing is an essential tool for communication, learning, and self-expression (Graham, 2006)[2]. Through writing, individuals are able to maintain personal links with friends, family, and colleagues from a distance (Graham, 2006). Writing also makes it possible to collect and convey information with accuracy and detail. Individuals can further record their ideas, reflect on their thoughts, or extend their knowledge on a topic through the use of writing.

Manuscript received October 9, 2015; revised December 17, 2015.

Maryam Shakoori, Parvin Kadivar, and Reza Sarami are with the Department of Educational Psychology of Kharazmi University, Tehran, Iran (e-mail: M.shakoori91@gmai.com, Kadivar220@yahoo.com, ghrsar2@gmail.com).
Learning to write is difficult especially for those who write in a second or a foreign language in academic context; they usually do not know enough about how to generate ideas for writing. Effective writing is considered to be a problem for EFL learners, so a need is to find out some ways of teaching that can help learners improve their effectiveness of writing skill. Writing is the primary medium by which teachers evaluate students' performance (Graham \& Harris, 1988)[3]. It also provides a flexible tool for assessing students' knowledge and academic competence in class and on high-stakes educational assessments (Graham \& Harris, 1988). Writing problems, therefore, make it difficult for students to reach their educational, occupational, and personal potential (Graham, 2006).

A study of O'Malley and Chamot (1990) [4] suggested that effective L2/FL learners are aware of the learning strategies they use and why they use them. Sturm and Rankin-Erickson (2002) [5] stated composing is an advanced academic task within educational settings and parts of the students' difficulties in writing are related to difficulties in applying various cognitive strategies. Sturm and Rankin-Erickson further stated that strategy instruction is a teaching approach that assists students in developing strategies for all phases of the writing process by breaking down writing tasks and making the sub processes and skills much more explicit. Two factors are regarded as the essence of the writing learning and instructing process: writers' writing proficiency and the writing strategy used in their planning process. First, the writers have their preferred learning-to-write and composing styles, while their writing proficiency could create obstacles during the writing process. Second, planning the process before writing has been taken as a baseline for setting goals, brainstorming, and organizing ideas (Flower \& Hayes, 1981)[1]. According to Oxford (1990)[6], a specific strategy can make learning easier, faster, and more enjoyable. A good writing strategy is expected to satisfy each writer's individual needs.

Concept maps can be utilized as a writing strategy for the satisfaction of the above two requirements.

Recently, concept mapping has been used as a tool for learning and teaching. Novak developed the notion of concept mapping in the1960s, in an attempt to represent visually the structure of information (Novak, 1991:45) [7]. Concept maps are tools that make ideas visual. They allow prior experience and understanding to be taken into consideration when building new concepts into the perceptual framework. By using concept maps, learners use their prior knowledge to understand the new concepts. It makes a link between unknown and known information that leads to deeper understanding (Novak, 2010) [8]. Concept mapping is a 
technique to let one person convey meaning and relationships to another person in a visual format, and concept maps have been shown to foster a joint understanding between two individuals viewing the same map. The concept map is believed to enhance recall and memory, aid in negotiation and balancing of conflicting needs, and create mutual understanding.

A concept map is a graphical map visualizing the relationship among concepts. It is a pre-task planning process that involves drawing diagrams of circled ideas and links connecting them (Fig. 1). Key components of concept maps are the propositional relationships or links, two or more concept labels linked by words that read as a unit. The links are usually action words explaining the meaning of the relationship. In the early stages of developing this skill, links may be less important than basic concept identification.

Novak and Cañas (2008) [9] claim that drawing this type of diagram allows writers to organize ideas in a hierarchical order by setting the most general information at the top of the diagram and the most specific ones at the bottom and see how one concept is related to another concept. Concept mapping relies heavily on cognitive theory and Ausubel's assimilation and meaningful learning theory (Novak \& Cañas, 2008). According to assimilation theory [10], learning is the most effective when new knowledge is related to previously learned material. According to this theory, the key determinant of an individual's learning was his/her previous knowledge. This theory took learning as most productive and meaningful when connecting prior knowledge with new information. That is, the acquisition of new knowledge hinged upon what was already known. He differentiated knowledge acquisition through "rote" learning and "meaningful" learning. Rote learning involves memorizing the material without processing it which allows easily forgetting. Meaningful learning, on the other hand, involves assimilation of new concepts and ideas with the learner's prior experience which is in line with the meaning-making process of generative learning.

According to Ausubel, meaningful learning occurs when a learner encounter clear, logically organized material and consciously tries to relate the new material to ideas and experiences stored in long term memory. Concept mapping, emphasizing well-organized and structured knowledge, facilitate meaningful learning and creation of powerful knowledge frameworks.

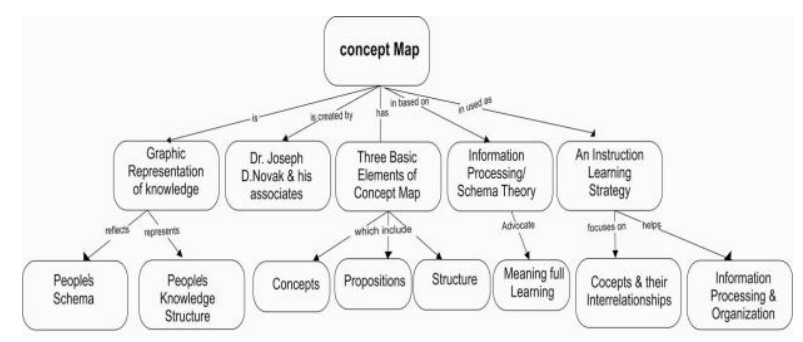

Fig. 1. A concept map of concept map (Wang, 2003) [11].

According to Schunk (1998) [12] students who believed they were learning a useful strategy were apt to feel efficacious about improving their writing, so strategies like concept mapping can cope with the problems (both linguistic and rhetorical) posed by the writing task as perceived by the writers. It makes writing interesting and less challenging for EFL learners because school writing is a cognitively demanding activity, often requiring students to carry out scarcely interesting tasks whose results are severely evaluated by teachers. Characteristics of writing tasks and classroom contexts, such as topic interestingness, relationship of writing to classroom activities and student personal experiences, student collaboration, and teacher attitude can affect writing (Boscolo \& Carotti, 2003; Boscolo \& Mason, 2001; Hidi \& Boscolo, 2006, 2007; Mason \& Boscolo, 2000; Oldfather \& Dahl, 1994) [12]-[18]; therefore a good strategy like concept mapping can makes this skill interesting and challenging. The concept map is believed to enhance recall and memory and create mutual understanding (Freeman, 2004) [19], so this graphical tool can facilitate the recall of vocabulary to use and make the written compositions easy to understand.

\section{Methodology}

\section{A. Design}

The study had a pretest-posttest control group design. Prior to the instruction of concept mapping strategy, both control and experimental groups were administered pretests in writing. To explore the effectiveness of concept mapping strategy both groups participated in posttests writing tasks at the end of the instructional period. Only the experimental group received the treatment.

\section{B. Participants}

28 EFL learners who were studying English as a foreign language at intermediate level in Danesh Gostar language academy and ranged from 12 to 18 years old were randomly assigned to the control group and experimental group.

The treatment for the experimental group was instruction and practice in concept mapping strategy. The Control group had the same number of teaching hours and followed the same course content except for concept mapping strategy.

\section{Instruments}

1) The writing part of preliminary English Tests (PET) ascribed to ESOL Cambridge tests for pre-posttest.

2) Strategy Instruction of concept mapping based on Harris and Graham's model (1996) [20].

\section{Procedure}

The strategy instruction of concept mapping started a week after the students participated in the pretest. They participated in twelve 75-minute study sessions. The students in the experimental group received the instruction for concept mapping strategy based on Harris and Graham (1996):

1) Strategy description: Concept mapping was described as a strategy that could be used to categorize information in a graphic form through drawing. Finally, the sequence of steps for creating a concept map was described.

2) Discussion of benefits of using the concept mapping strategy in writing compositions: Students were asked two goals and purposes. The teacher discussed the students about the significance and benefits of using the concept mapping strategy in writing compositions. Students were asked two questions: 1) how do you think 
this strategy might help you write? And 2) how could this strategy help you with different types of writing?

3) Modeling the strategy: The teacher modeled use of concept mapping strategy by creating a map while students were offered several topics to select from for the activity. Once the group agreed on a topic, the teacher wrote it on the white board. This topic was labeled as "main idea" of the concept map. Next possible subtopics were generated. Students were taught how to write subtopic information in telegraphic form. The teacher modeled use of telegraphic language forms and explained that this involves choosing the most important information. Upon completion of the map, the teacher modeled the transfer of subtopic information from the map into written form instruction followed the sequence of procedures for transferring concept maps into written paragraphs, starting with top-level structures i.e., topics and subtopics), the teacher reviewed the information on the map. The teacher modeled how she would rewrite the information from the map into complete sentences. Finally, the concluding paragraph was explained and with the help of the students the teacher wrote a concluding paragraph.

4) Student mastery of strategy steps: During this stage, students rehearsed and memorized the sequence of activities for concept map construction.

5) Guided practice and Feedback: During these sessions, feedback was provided for students' performance. Students chose a topic and created maps. Then, they used the concept maps to compose essays.

The Control group was devoted the same amount of time for teaching writing and the same homework assignments, but these did not include concept mapping strategy. At the end of the instruction both group composed nearly 20 texts of different topics. A week after the instruction period of the strategy of concept mapping, posttest was run to the students in two groups and they filled in CIS survey again.

\section{RESUlTS AND DISCUSSION}

A comparison of mean scores of the experimental group and the control group on posttests shows that the participants in the experimental group outperformed on post essay writing tests in comparison with the control group. To explore the significant differences in the performances of the two groups, an ANCOVA on Post writing achievement scores by group (experimental vs. control), using Pre writing achievement scores as a covariate, was run. The results of the ANCOVA ( $F$ $=87.475, p=.0001<.05)$ indicated that the difference between the two groups is significant. In other words, it shows that there is a significant difference in the posttest scores of writing achievement between the two groups (Table I), so concept mapping can be an effective strategy for improvement of writing skill among EFL learners.

This research explored the effect of concept maps as a pre-writing strategy on improvement of writing achievement and interest in instruction of English among EFL learners at intermediate level .The result was in agreement with other studies which reported concept mapping as an effective and helpful instructional tool for teaching writing (Machida, Dalsky, 2014; Cho \&Lee, 2010; Ibrahim. M.R, 2014; Ojima, 2006; Nobahar, 2013; Pishghadam \& Ghanizadeh, 2006; Fahim \& Rahimi, 2011; Chiou, 2008) [21]-[28].

TABLE I: THE EstimATE OF THE EFFECT OF THE GROUP AND THE PRETEST FOR WRITING ACHIEVEMENT

\begin{tabular}{|l|l|l|l|l|l|}
\hline source & Sum of squares & $d f$ & Mean square & $F$ & Sig. \\
\hline Pretest & $\mathbf{1 9 . 8 9 8}$ & $\mathbf{1}$ & $\mathbf{1 9 / 8 9 8}$ & $\mathbf{1 5 4 / 1 3 5}$ & $\mathbf{0} / \mathbf{0 5 5}$ \\
\hline Group & $\mathbf{4 2 9 / 4 8 4}$ & $\mathbf{1}$ & $\mathbf{4 2 9 . 4 8 4}$ & $\mathbf{8 7 / 4 7 5}$ & $0 / \mathbf{0 0 0 1}$ \\
\hline Error & $\mathbf{1 2 2 / 7 5 4}$ & $\mathbf{2 5}$ & $\mathbf{4 . 9 1 0}$ & - & - \\
\hline Sum of revised & $\mathbf{6 8 2 / 9 6 4}$ & $\mathbf{2 7}$ & - & - & - \\
\hline
\end{tabular}

Freeman (2004) provides an explanation for the effect of concept mapping strategy on the writing process. Freeman states that human minds have the ability to create conceptual objections from the concrete to abstract by the process of mapping from past to present. The ability to create multiple mappings of mental spaces enables us to construct new conceptualizations of the world and create abstract thoughts in the world; it can reduce miscommunication and lack of clarity in written texts. As Rankin-Erickson (2002) stated earlier that this tool assists the learners to write confidently by breaking down writing tasks and making the sub processes and skills much more explicit. It can make the EFL learners proficient and confidant enough to write essays in different kinds of writing styles. A good concept map can function as a graphic organizer visualizing not only a writer's ideas for a specific writing topic, but also the connected relationships among the ideas (Sturm \& Rankin- Erickson, 2002). In other words, the map indicates individual writer's concept processing. With the assistance of maps, writers can examine what ideas are missing or irrelevant in their writings themselves. As a result, writers can refer to the maps drawn at the planning stage and make the writing process work efficiently. Moreover, the visual feature of concept maps can build communication among different writers, map-drawers, and the instructor. To conclude, concept maps enable different writers to construct and organize their ideas in the pre-writing phase; moreover, the visual feature of maps helps mutual understanding. Thus training in concept maps helps learners enhance their writing skills (Sturm \& Rankin-Erickson, 2002).

The findings also support Schunk's (1998) claim holding that students who believe they are learning a useful strategy are apt to feel efficacious about improving their writing. In teaching creative writing, we do try to help our students find their inner wellspring of inspiration. However, to write well, one still needs to learn and understand a certain number of 
essential concepts. As such, part of learning to write successfully is learning to appreciate how other writers have used such concepts. Even here, therefore, concept mapping can prove invaluable for any student of writing.

\section{REFERENCES}

[1] L. Flower and J. R. Hayes, "A cognitive process theory of writing," College Composition and Communication, pp. 365-387, 1981.

[2] I. D. Graham, J. Logan, M. B. Harrison et al., "Lost in knowledge translation: Time for a map?" Journal of Continuing Education in the Health Professions, vol. 26, no. 1, pp. 13-24, 2006.

[3] S. Graham and K. R. Harris, "Instructional recommendations for teaching writing to exceptional students," Exceptional Children, vol 54, no. 6, pp. 506-512, 1988.

[4] J. M. O'malley and A. U. Chamot, Learning Strategies in Second Language Acquisition, Cambridge University Press, 1990.

[5] J. M. Sturm and J. L. Rankin-Erickson, "Effects of hand-drawn and computer-generated concept mapping on the expository writing of middle school students with learning disabilities," Learning Disabilities Research \& Practice, vol. 17, no. 2, pp. 124-139, 2002.

[6] R. Oxford, D. Crookall et al., "Strategy training for language learners: Six situational case studies and a training model," Foreign Language Annals, vol. 23, no. 3, 197-216, 1990.

[7] J. D. Novak and D. Musonda, "A twelve-year longitudinal study of science concept learning," American Educational Research Journal, vol. 28, no. 1, pp. 117-153, 1991

[8] J. D. Novak, Learning, Creating, and Using Knowledge: Concept Maps as Facilitative Tools in Schools and Corporations, Routledge, 2010.

[9] J. D. Novak and A. J. Cañas, The Theory Underlying Concept Maps and How to Construct and Use Them, Technical Report. Institute for Human and Machine Cognition, Pensacola, 2008.

[10] D. P. Ausubel, J. D. Novak, and H. Hanesian, Educational Psychology: A Cognitive View, New York: Holt, 1968.

[11] C. X.-X. Wang, "The instructional effects of prior knowledge and three concept mapping strategies in facilitating achievement of different educational objectives," Doctoral dissertation, The Pennsylvania State University, 2003.

[12] D. H. Schunk and B. J. Zimmerman, Self-regulated Learning: From Teaching to Self-reflective Practice, New York: Guilford Press, 1998.

[13] P. Boscolo and L. Carotti, "Does writing contribute to improving high school students' approach to literature?" L1-Educational Studies in Language and Literature, vol. 3, no. 3, pp. 197-224, 2003.

[14] P. Boscolo and L. Mason, "Writing to learn, writing to transfer," Writing as a Learning Tool, Springer Netherlands, 2001, pp. 83-104.

[15] S. Hidi and P. Boscolo, "Motivation and writing," Handbook of Writing Research, 2006, pp. 144-157.

[16] P. Boscolo and S. Hidi, "The multiple meanings of motivation to write," Writing and Motivation, vol. 19, no. 1, 2007.

[17] L. Mason and P. Boscolo, "Writing and conceptual change. What changes?" Instructional Science, vol. 28, no. 3, pp. 199-226, 2000.

[18] P. Oldfather and K. Dahl, "Toward a social constructivist reconceptualization of intrinsic motivation for literacy learning," Journal of Literacy Research, vol. 26, no. 2, pp. 139-158, 1994.
[19] L. A. Freeman and L. M. Jessup, "The power and benefits of concept mapping: measuring use, usefulness, ease of use, and satisfaction," International Journal of Science Education, vol. 26, no. 2, 151-169 2004.

[20] C. M. Levy and S. Ransdell, The Science of Writing: Theories, Methods, Individual Differences and Applications, Routledge, 2013.

[21] N. Machida and D. J. Dalsky, "The effect of concept mapping on L2 writing performance: Examining possible effects of trait-level writing anxiety," English Language Teaching, vol. 7, no. 9, p. 28, 2014.

[22] Y. Lee and S. Cho, "Using concept map prewriting strategies in Korean writing classes," Korean Language in America, pp. 46-61, 2010.

[23] I. M. Al-Shaer, "Employing concept mapping as a pre-writing strategy to help EFL learners better generate argumentative compositions," International Journal for the Scholarship of Teaching \& Learning, vol. 8, no. 2, 2014.

[24] M. Ojima, "Concept mapping as pre-task planning: A case study of three Japanese ESL writers," System, vol. 34, no. 4, pp. 566-585, 2006

[25] B. Nobahar, A. R. N. Tabrizi, and M. Shaghaghi, "The effect of concept mapping on Iranian intermediate EFL learners' self-efficacy and expository writing accuracy," Theory and Practice in Language Studies, vol. 3, no. 11, pp. 2117-2127, 2013.

[26] R. Pishghadam and A. Ghanizadeh, "On the impact of concept mapping as a prewriting activity on EFL learners' writing ability," Iranian Journal of Applied Linguistics, vol. 9, no. 2, pp. 101-126, 2006.

[27] M. Fahim and A. H. Rahim, "The effect of concept mapping strategy on the writing performance of EFL learners," Journal of Academic and Applied Studies, vol. 1, no. 5, pp. 1-8, 2011.

[28] C. C. Chiou, "The effect of concept mapping on students' learning achievements and interests," Innovations in Education and Teaching International, vol. 45, no. 4, pp. 375-387, 2008.

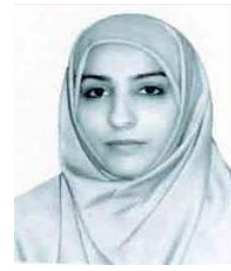

Maryam Shakoori was born in Tehran, Iran in 1984 She got her BA in English language and literature from University of teacher training, Sabzevar in 2007 and the MA in educational psychology from University of Kharazmi, Tehran in 2015

She is manager of a foreign languages institute in Tehran and has taught English since 2007. She is interested in research of learning and instruction especially EFL and new methods, so extremely interested in pursuing a $\mathrm{PhD}$ degree in educational psychology.

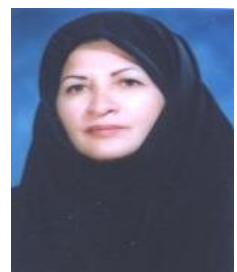

Parvin Kadivar was born in Abadeh, Iran in 1944 She graduated with a BS. She completed a master degree in University of Tehran and a PhD degree in educational psychology in University of Missouri-Columbia (UMC), USA in 1980

As a faculty of Psychology Department, she attended in Kharazmi University in Tehran since 1980. Her research interest is learning and development. She has authored several textbooks and articles in educational psychology. 